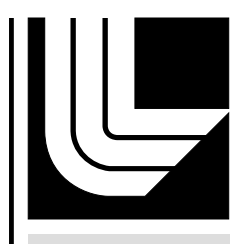

LAWRENCE LIVERM ORE N A TIO N A L LABORATORY

Improvised Nuclear Device Case Study

B. Buddemeier, N. Suski

July 14, 2011 
This document was prepared as an account of work sponsored by an agency of the United States government. Neither the United States government nor Lawrence Livermore National Security, LLC, nor any of their employees makes any warranty, expressed or implied, or assumes any legal liability or responsibility for the accuracy, completeness, or usefulness of any information, apparatus, product, or process disclosed, or represents that its use would not infringe privately owned rights. Reference herein to any specific commercial product, process, or service by trade name, trademark, manufacturer, or otherwise does not necessarily constitute or imply its endorsement, recommendation, or favoring by the United States government or Lawrence Livermore National Security, LLC. The views and opinions of authors expressed herein do not necessarily state or reflect those of the United States government or Lawrence Livermore National Security, LLC, and shall not be used for advertising or product endorsement purposes.

This work performed under the auspices of the U.S. Department of Energy by Lawrence Livermore National Laboratory under Contract DE-AC52-07NA27344. 


\title{
Improvised Nuclear Device Case Study
}

\author{
An Analytic Framework for Disaster Management
}

\author{
Brooke Buddemeier \\ Nancy Suski \\ Lawrence Livermore National Laboratory \\ Livermore, CA, USA
}

\begin{abstract}
Reducing the casualties of catastrophic terrorist attacks requires an understanding of weapons of mass destruction (WMD) effects, infrastructure damage, atmospheric dispersion, and health effects. The Federal Planning Guidance for Response to a Nuclear Detonation provides the strategy for response to an improvised nuclear device (IND) detonation. The supporting science developed by national laboratories and other technical organizations for this document significantly improves our understanding of the hazards posed by such an event. Detailed fallout predictions from the advanced suite of three-dimensional meteorology and plume/fallout models developed at Lawrence Livermore National Laboratory, including extensive global geographical and real-time meteorological databases to support model calculations, are a key part of response planning.
\end{abstract}

This presentation describes the methodology and results to date, including visualization aids developed for response organizations. These products have greatly enhanced the community planning process through first-person points of view and description of the dynamic nature of the event.

Keywords-improvised nuclear device; disaster management; emergency response; radiological hazard; blast analysis

\section{INTRODUCTION}

The federal government acting alone can neither secure the nation nor respond to major disasters or terrorist events. The Quadrennial Homeland Security Review [1] and Federal Emergency Management Agency (FEMA) Strategic Plan [2] recognize that the homeland security "enterprise" includes shared responsibilities and depends on the collective efforts of federal, state, local, tribal, territorial, nongovernmental, and private-sector partners - as well as individuals, families, and communities. Many of the threats we face are difficult, if not impossible, to predict or prevent. Disaster-management strategies will be affected by many factors, including, global interdependencies, technical innovation and dependency, the evolving terrorist threat, and the changing role of the individual. Meeting these challenges requires much more sophisticated methodologies and innovative approaches to mitigating potential hazards, developing effective response plans, and putting in place the capability to rapidly recover.

Preparing for a catastrophic event is quantitatively different in terms of mass casualties and fatalities, infrastructure damage, and disruption of life-sustaining services. For complex technical threats involving weapons of mass destruction (WMD), actions taken now to understand and plan for the immediate aftermath of such an event will be critical to saving lives and rebuilding communities. The Disaster Management Analytic Framework (DMAF) enables emergency planners to quantify and visualize the impact of a significant WMD incident. DMAF provides insights that can lead to more effective response operations and be applied to other catastrophic planning activities.

Scenario \#1 of the 15 Department of Homeland Security (DHS) national planning scenarios is an improvised nuclear device (IND) detonation in the national capital region. An effective response involves managing a large-scale incident, including mass-casualty, mass-evacuation, and massdecontamination issues. Preparedness planning activities based on this scenario present difficult challenges in time-critical decision making; the need to coordinate large-scale response operations across multiple jurisdictions; and the need to effective respond with limited infrastructure and resources. A DMAF for scenario \#1 was utilized to define key characteristics of the event and aid response planning.

In 2007, the U. S. Congress expressed concern that cities have little guidance to help them prepare their populations for the critical moments shortly after a nuclear terrorism event. They directed the DHS, Office of Health Affairs (OHA) to work with the National Academies Institute of Medicine, the Homeland Security Institute, the national laboratories, and state and local response organizations to address this issue [3]. The OHA initiative is currently managed by the FEMA as part of a coordinated federal effort to improve response planning for a nuclear detonation.

\section{NEED FOR PlanNING GUIDANCE}

Federal protective action guidance [4] currently exists for radiation exposure; however, the focus has been concentrated on avoiding relatively low-level exposures to decrease the risk of cancer from an accidental transportation or nuclear power plant release. The 2006 Federal Register Notice published by DHS [5], which clarified how existing protective action guidance can be applied for radiological and nuclear terrorism, did not specifically address guidance for the acute effects of a domestic nuclear explosion. The Cold War civil defense program can help with some insights and advice, but many of the paradigms no longer apply. For example, the concept of a fallout shelter worked well with a few minutes warning of incoming missiles, but its applicability is less clear for an attack that occurs without any notice. There also appeared to be 
a lack of scientific consensus on the appropriate actions to take after a nuclear detonation. For example, the recommendations of DHS's Ready.gov, which are consistent with the recommendations of the National Academy of Sciences [6], were recently criticized by the Federation of American Scientists [7] because of conflicting recommendations with a RAND study [8].

The work presented here attempts to update the Cold War guidance to address the asymmetric threat we now face. Both our society and our cities have changed significantly over the last half-century, and new preparedness guidance is required.

\section{METHODOLOGY}

This study identifies key planning considerations and response strategies associated with response to a nuclear detonation. These strategies are designed to protect response personnel, provide regional situational assessment, and support public health and safety. A capabilities-based planning approach utilized extensive modeling and technical analysis and discussions with almost 500 emergency responders from across the nation to develop key response planning factors. The DMAF provides a common foundation that facilitates the development of strategic response priorities and enables a more collaborative, transparent, and responsive analysis for planning scenarios. Every community has unique requirements and may reasonably adopt different response strategies based on the same analysis. For example, the importance of early, adequate shelter followed by informed evacuation as a key public protection strategy will be applied differently in a community that lacks an abundance of adequate shelters or effective evacuation routes.

To resolve conflicts in the technical community and create a coordination point for research, DHS formed the IND Modeling and Analysis Coordination Working Group (MACWG). Membership includes national laboratories, technical organizations, and federal agencies. The purpose of the MACWG is to establish scientific consensus (where possible) on nuclear weapons effects; bound uncertainties and identify unknowns; and resolve conflicts with respect to recommended response actions. The MACWG brought together the collective capabilities in nuclear-weapon effects modeling, atmospheric transport and dispersion, radiation health physics, and blast and shelter analyses to create a scientific basis for IND response planning. The MACWG has enabled better coordination within the federal, state, and local community and has provided a venue in which to discuss critical scientific and technical issues that must be resolved to save lives and ensure resilience to disasters.

\section{NUCLEAR DETONATION EFFECTS}

The basic anatomy of a nuclear explosion is well known and documented in literature such as Glasstone's The Effects of Nuclear Weapons [9] and NATO documents [10]. Mitigating the impact of a domestic nuclear explosion requires a basic understanding of key effects. These effects can be broken into two main components: prompt and delayed. As an example, the effects identified below are approximate for a ten kiloton (10kt) nuclear explosion in a large city like Washington, DC. This is consistent with the national planning scenario \#1 and with early

The research and efforts discussed in this article have been supported by the Department of Homeland Security's Science and Technology Directorate and the Federal Emergency Management Agency. nuclear weapons such as those used on Hiroshima and Nagasaki.

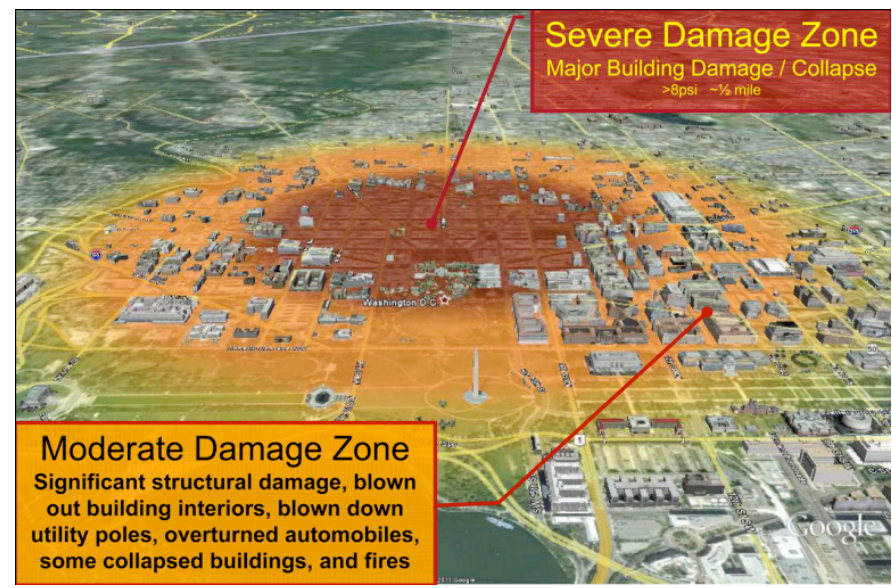

Figure 1. Damage zones resulting from a domestic nuclear detonation

Primary among prompt effects is blast (Fig. 1). A 10kt explosion is equivalent to 5,000 truck bombs like the one used to destroy the Murrah building in the 1995 Oklahoma City bombing [11]. Blast will damage or destroy most buildings within a half-mile of the detonation location, and it is unlikely that the population in this area would survive. From a half-mile to about a mile out, survival will mostly likely depend on the type of structure a person was in when the blast occurred. Even at a mile, the blast wave will have enough energy to overturn some cars and severely damage some light structures.

A mile from the detonation is also the approximate distance at which a person outdoors could receive a significant exposure of initial ionizing radiation. The closer to the detonation point, the higher the exposure. The same is also true for an outdoor individual's exposure to the thermal pulse from the detonation, which may also cause burns to exposed skin out to this range, and possibly further on a day with good visibility. Both of these effects are reduced for people inside buildings or in the shadow of buildings in the urban area.

In addition to ionizing and thermal radiation, the detonation creates a brilliant flash of light that can cause temporary blindness to those outdoors over 5 miles away. This effect could go further if there is good visibility or clouds to reflect the light, or if the event occurs at night. "Flash blindness" can even occur if the victim is not looking in the direction of the detonation. It can last several seconds to minutes. Although this effect does not cause permanent damage, the sudden loss of vision to drivers and pilots could cause a large number of traffic casualties and make many roads impassable.

Another long-range prompt effect, which is poorly understood, is glass breakage. Most of the injuries outside of the Murrah building in the 1995 Oklahoma City bombing were caused by this phenomenon [12]. Extrapolating from more recent work on conventional explosives [13], a 10kt explosion could break certain types of windows (e.g., large monolithic annealed) over 8 miles away. Also noted in this same study was the tendency for glass to fail catastrophically even at extreme ranges, causing severe injury to those behind it. NATO medical-response planning documents [10] for nuclear 
detonations state that "...missile injuries will predominate. About half of the patients seen will have wounds of their extremities. The thorax, abdomen, and head will be involved about equally." A significant number of victims from Nagasaki arriving at field hospitals exhibited glass-breakage injuries [14].

The primary delayed effect from a ground-level nuclear detonation is from "fallout" (Fig. 2). Fallout is generated when the dust and debris excavated by the explosion is combined with radioactive fission products and drawn upward by the heat of the event. This cloud rapidly climbs through the atmosphere, up to 5 miles high for a 10kt, and highly radioactive particles coalesce and drop back down to earth as it cools. It is important to note that Hiroshima and Nagasaki did not have significant fallout because their detonations occurred at altitude.

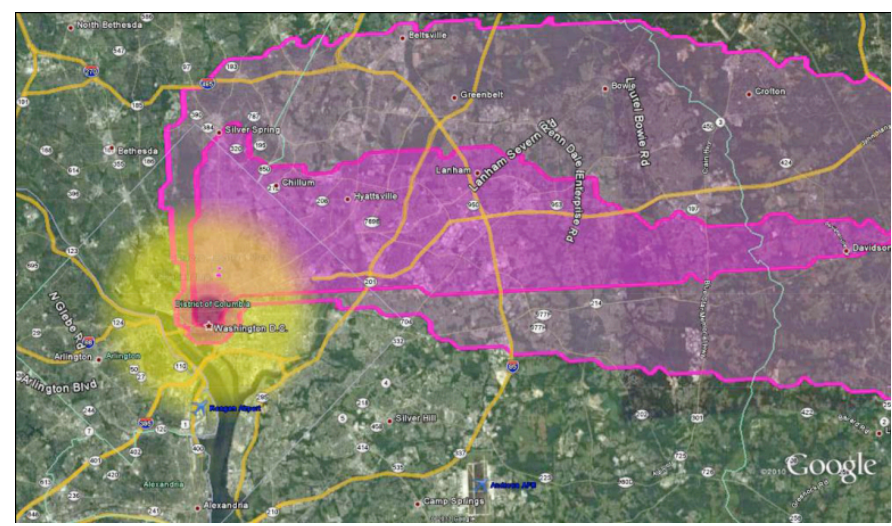

Figure 2. Example of fallout pattern from a 10kT ground-level detonation

The hazard from fallout comes not from breathing the particles, but from being exposed to the ionizing radiation they give off after they have settled on the ground and building roofs. Radiation levels from these particles will drop off quickly: most $(55 \%)$ of the potential exposure occurs in the first hour, and $80 \%$ occurs within the first day. Although it is highly dependent on weather conditions, the most dangerous concentrations of fallout particles (i.e., potentially fatal to those outside) occur within 10 miles downwind of the event and are clearly visible as they fall, often the size of fine sand or table salt [15].

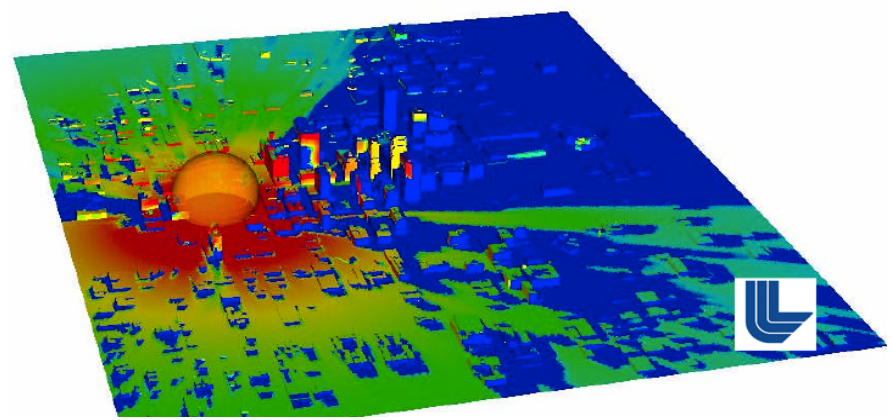

Figure 3. Integrated thermal flux from a 10kt ground-level nuclear detonation in a small U.S. city

\section{RECENT RESEARCH}

The results of recent modeling [16] indicate that a modern urban environment can greatly mitigate some of the effects of a low-yield nuclear detonation. For example, thermal burns from the heat of the initial explosion, primarily a line-of-sight phenomenon, can be greatly reduced in an urban environment where structures can block the thermal radiation. Fig. 3 shows how building shadows can protect the outdoor population from significant thermal exposure by modeling conducted at Lawrence Livermore National Laboratory [17].

Models developed at Applied Research Associates (ARA) and Los Alamos National Laboratory have shown similar reductions in injuries from the initial radiation produced in the first minute of a nuclear explosion. Fig. 4 [18] demonstrates the nonsymmetrical reduction in radiation exposure by the urban environment. The left side of the image represents an unobstructed exposure from a $10 \mathrm{kT}$ surface detonation as compared to the reduction of outdoor radiation levels indicated in the right side of the image. Like the thermal analysis, these studies indicate that the ambient radiation levels from a lowyield, ground-level nuclear detonation in an urban environment could be significantly reduced. For example, the unobstructed range for a potentially lethal radiation exposure of 400 rads (cGy) is about 1,200 yards. Initial results by ARA indicate that the range might be reduced by as much as half, down to 500 to 700 yards from the detonation point in highly built-up areas.

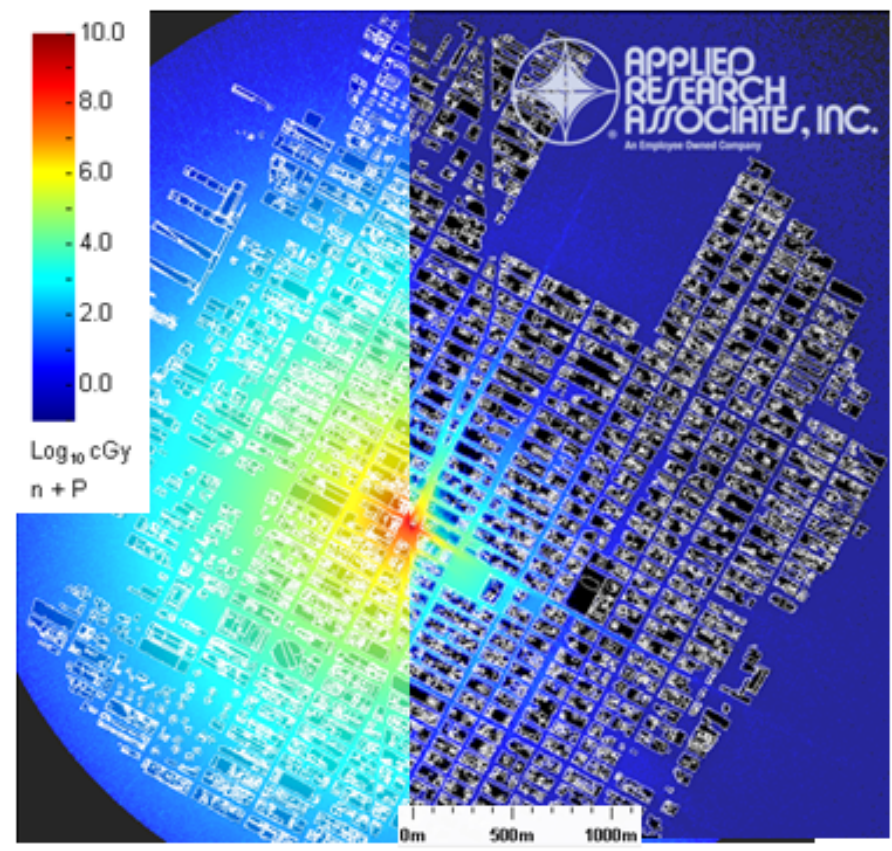

Figure 4. Analaysis of the reduction of prompt radaition in the urban environment

Unlike prompt effects, which occur too rapidly to avoid, health effects from fallout can be mitigated by leaving the area before the fallout arrives or by taking shelter from it. Although some fraction of ionizing radiation can penetrate buildings, shielding offered by walls and distance from outdoor fallout particles can easily reduce exposures by a factor of 10 or more, even in common urban buildings.

The quality of shelter is defined by a protection factor (PF), which is equal to the ratio of outside dose rate divided by inside dose rate. Like sunscreen's SPF, the higher the PF value, the 
lower the exposure compared to the exposure of an unsheltered person in the same area. Fig. 5 shows sample PF estimates based on evaluations conducted circa 1960 for typical structures during that era.

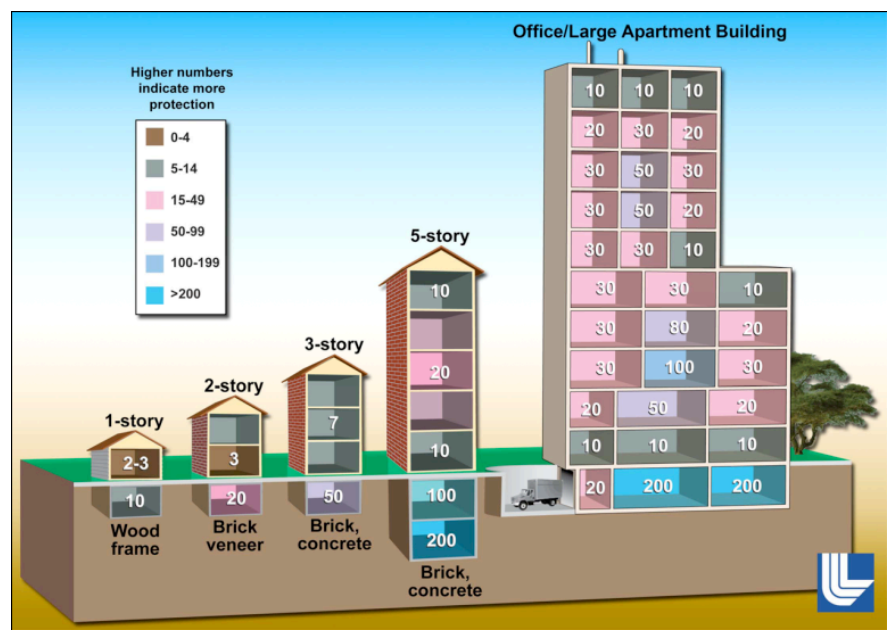

Figure 5. PF by building and by location within building

Efforts are under way to update our understanding of the level of protection that modern buildings could provide from fallout radiation. Fig. 6 shows an analysis of a modern, three-story office building (left), in which most of the first floor locations had PFs of 10 (shown as light colored areas near the border of the building ); PF 10 (green) is considered adequate. Most areas in the building provided even better protection, with PFs higher than 100 (darkest areas inside the building) [19].

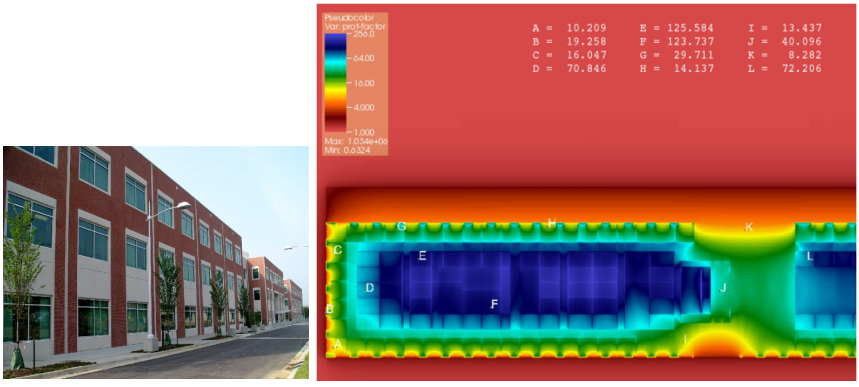

Figure 6. Protection provided by a typical modern building. Source: Images courtesy of Oak Ridge National Laboratory

Scientists at Lawrence Livermore National Laboratory are developing the capability to assess the quality of urban shelter with respect to nuclear fallout. With the results of this assessment (see Fig. 7), planners and responders can estimate: (a) the protection provided by existing buildings to fallout radiation, (b) the effectiveness of several shelter strategies that utilize existing buildings, and (c) the radiation exposures if these shelter strategies were to be used.

Experts at Sandia National Laboratory have analyzed various evacuation strategies to determine the optimum strategy under a variety of conditions [21-23].

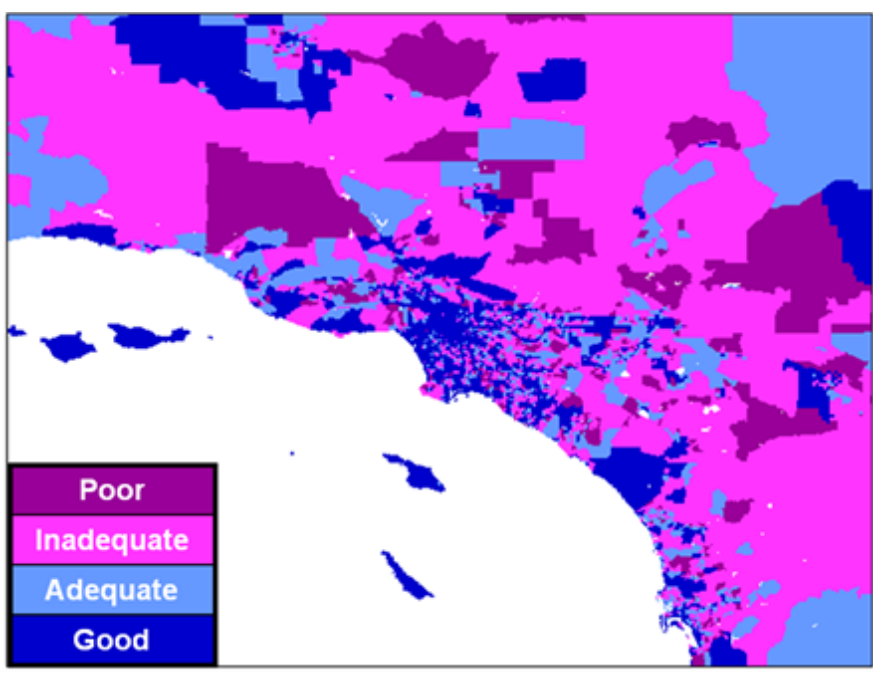

Figure 7. Illustrative evaluation of the protection offered by local (nearby) shelter in the Los Angeles Basin [20]

Other effects, such as the electromagnetic pulse (EMP) and fires, also need to be considered in response planning and are areas of ongoing research. For a ground-level detonation, most EMP effects will be limited to the blast-damage zones, with a few, random, longer-range disruptions occurring a few miles beyond. Although the possibility of a "firestorm" is unlikely given modern construction, there will be a large number of small, disparate fires started from thermal and blast effects (generally around the 1-mile perimeter), which could spread and coalesce if not mitigated. [24]

\section{KEY ResPonse PlanNING FACTORS}

As stated in the outset of this paper, the end goal of this activity is to build the scientific foundation for large-scale disasters utilizing a nuclear detonation as case study. The Planning Guidance for Response to a Nuclear Detonation, $2^{\text {nd }}$ Edition, produced by Federal interagency committee led by the Executive Office of the President [16] is the result of a collaborative effort across many federal departments and agencies. It utilized some of the latest research discussed in this paper and identifies key recommendations in order to respond to and recover from an IND incident. The document identified a zoned approach to facilitate response planning, with the key zones defined as:

- Light Damage Zone: Windows mostly broken, injuries requiring self- or outpatient-care.

- Moderate Damage Zone: Significant building damage and rubble, downed utility poles, overturned automobiles, fires, many serious injuries; greatest lifesaving opportunities.

- Severe Damage Zone: Most buildings destroyed; radiation prevents entry into the area; lifesaving not likely.

- Dangerous Fallout Zone: An area where large doses could be delivered to unsheltered the public and emergency responders in a short period of time. This is the dark purple area in Fig. 2. 
- $\quad 0.01 \mathrm{R} / \mathbf{h}$ Boundary: The areas where emergency operations can be safely performed provided that responders take appropriate planning and dose monitoring and control measures. This is the light purple area in Fig. 2.

Key Response Planning Factors for the Aftermath of Nuclear Terrorism [25] begins to provide the scientific basis necessary to achieve these response objectives:

- Seek adequate shelter-the most critical lifesaving action for the public and responders is to seek adequate shelter (PF of 10 or more) for at least the first hour.

- Protect response personnel-initial responder efforts should be spent on making high-range dose-rate measurements within their shelter.

- Support regional situation assessment.

- Develop an informed evacuation strategy.

- Control fires-watch for firestorm warning signs; prioritize facilitated evacuation near large fires; use airborne fire-control methods.

The National Council of Radiation Protection and Measurement Report Number 165 [26] provides additional scientific backing for the response strategies discussed above.

\section{CONCLUSION}

Recent advances in analyzing the effects of a nuclear detonation in an urban area have addressed a number of difficult issues and greatly improved our ability to reduce the consequences of such a horrific event. However, considerable research challenges remain. Many of these challenges have been documented in [24]. The DMAF used for this scenario can be applied to a variety of natural and manmade catastrophic events involving large-scale incident response. DMAF facilitates scientific consensus and the development of comprehensive planning guidance in support of emergency managers and response operations.

\section{ACKNOWLEDGMENTS}

Lawrence Livermore National Laboratory (LLNL) would like to acknowledge the leadership and expertise of the Department of Homeland Security's Patricia Underwood (Science and Technology), Don Daigler, Chad Gorman, Sean Crawford, and Steve Chase (FEMA). The authors gratefully acknowledge the insights and support of the Modeling and Analysis Coordination Working Group, a technical working group collaborating on key aspects of nuclear effects modeling whose member include the following contributors; Michael Dillon, John Nasstrom, Kevin Foster, Steve Homann and Gayle Sugiyama at Lawrence Livermore National Laboratory; Larry Brandt and Ann Yoshimura at the Sandia National Laboratories; Steve Maheras at the Pacific Northwest National Laboratory; Kyle Millage and Joe Madrigal at Applied Research Associates; Jeffery Johnson at Oak Ridge National Laboratory.

This work performed under the auspices of the U.S. Department of Energy by Lawrence Livermore National Laboratory under Contract DE-AC52-07NA27344. The Department of Homeland Security sponsored part of the production of this material under the same contract.

\section{DISCLAIMER}

This document was prepared as an account of work sponsored by an agency of the United States government. Neither the United States government nor Lawrence Livermore National Security, LLC, nor any of their employees makes any warranty, expressed or implied, or assumes any legal liability or responsibility for the accuracy, completeness, or usefulness of any information, apparatus, product, or process disclosed, or represents that its use would not infringe privately owned rights. Reference herein to any specific commercial product, process, or service by trade name, trademark, manufacturer, or otherwise does not necessarily constitute or imply its endorsement, recommendation, or favoring by the United States government or Lawrence Livermore National Security, LLC. The views and opinions of authors expressed herein do not necessarily state or reflect those of the United States government or Lawrence Livermore National Security, LLC, and shall not be used for advertising or product endorsement purposes. 


\section{REFERENCES}

[1] Department of Homeland Security, Quadrennial Homeland Security Review, 2010.

[2] Department of Homeland Security, FEMA Strategic Plan, 2011.

[3] House of Representatives, 2007, Making Emergency Supplemental Appropriations for the Fiscal Year Ending September 30, 2007, and for Other Purposes, Report 110-107, April 24, 2007.

[4] National Council on Radiation Protection and Measurements, 1982, The Control of Exposure of the Public to Ionizing Radiation in the Event of Accident or Attack. National Council on Radiation Protection Symposium proceedings (Session B, Topic 4).

[5] DHS, Planning Guidance for Protection and Recovery Following Radiological Dispersal Device (RDD) and Improvised Nuclear Device (IND) Incidents issued in the Federal Register (Vol. 73, No. 149, pp. 45029-45049), August 1, 2008.

[6] National Academy of Sciences, 2005, Nuclear Attack, factsheet created for News and Terrorism: Communicating in a Crisis.

[7] Federation of American Scientists, 2006, Analysis of Ready.gov. Available online: http://www.fas.org/reallyready/analysis.html.

[8] L. Davis, T. LaTourrette, D. E. Mosher, L. M. Dais, and D. R. Howell, 2003, Individual Preparedness and Response to Chemical, Radiological, Nuclear, and Biological Terrorist Attacks [Electronic version]. Arlington, Virginia: RAND Corporation.

[9] S. Glasstone and P. J. Dolan, 1977, The Effects of Nuclear Weapons (third edition). Washington, D.C.: U.S. Government Printing Office, Available online (PDF).

[10] NATO, 1996, NATO Handbook on the Medical Aspects of NBC Defensive Operations (Part I - Nuclear). Departments of the Army, Navy, and Air Force: Washington, D.C.

[11] P. F. Mlakar, Sr., W. G. Corley, M. A. Sozen, and C. H. Thornton, August 1998, "The Oklahoma City Bombing: Analysis of Blast Damage to the Murrah Building." Journal of Performance of Constructed Facilities 12(3): pp. 113-119.

[12] Safety Solutions, Posted: 15 October 2005, "Preventing glass from becoming a lethal weapon." www.safetysolutions.net.au, Retrieved on November 1, 2007.

[13] Applied Research Associates, Inc., Injury based glass hazard assessment: range-to-effect curves, Sponsored by US Army Technical Center for explosives Safety, DACA45-02-D-0004.

[14] Departments of the Army, Navy, and Air Force: Washington, D.C.

[15] National Council on Radiation Protection and Measurements, 1982, The Control of Exposure of the Public to Ionizing Radiation in the Event of Accident or Attack. NCRP Symposium proceedings (Session B, Topic 4).
[16] B. Buddemeier, Reducing the Consequences of a Nuclear Detonation: recent Research, The Bridge Journal, National Academy of Engineering, Summer 2010.

[17] R. E. Marrs, W. C. Moss, and B. Whitlock, 2007, Thermal Radiation from Nuclear Detonations in Urban Environments, UCRL-TR-231593. A report for Lawrence Livermore National Laboratory, Livermore, CA. (For recent updates on this work, contact Brooke Buddemeier at brooke2@1lnl.gov.)

[18] J. Bergman, K. Kramer, B. Sanchez, J. Madrigal, K. Millage, and P. Blake, The Effects of the Urban Environment on the Propagation of Prompt Radiation Emitted from an Improvised Nuclear Device, $56^{\text {th }}$ Annual Meeting of the Health Physics Society, June 29, 2011.

[19] J. O. Johnson, et al., Assessment of Building Protection Factors for Fallout Radiation due to an IND Urban Detonation, Oak Ridge National Laboratory, April 2010. (For more information contact the author at johnsonjo@ornl.gov.)

[20] J. S. Nasstrom, K. T. Foster, P. Goldstein, M. B. Dillon, N. G. Wimer, S. Homann, and G. Sugiyama, Advances in Modeling Radiation Dispersal Device and Nuclear Detonation Effects, ANS EPRRSD, 13th Robotics and Remote Systems for Hazardous Environments, 11th Emergency Preparedness and Response, Knoxville, TN, August 7-10, 2011, American Nuclear Society, LaGrange Park, IL (2011), LLNLCONF-486512.

[21] L. D. Brandt, Mitigation of Nuclear Fallout Risks Through Sheltering and Evacuation. Report, SAND2009-7367C, November 18, 2009. Sandia National Laboratories, Albuquerque, NM (For more information email lbrandt@sandia.gov.)

[22] L. D. Brandt and A. S. Yoshimura, Analysis of Sheltering and Evacuation Strategies for an Urban Nuclear Detonation Scenario. Report, SAND2009-3299, June 2009. Sandia National Laboratories, Albuquerque, NM (For more information email lbrandt@sandia.gov.)

[23] L. D. Brandt and A. S. Yoshimura, Nuclear Evacuation Analysis Code (NUEVAC): A Tool for Evaluation of Sheltering and Evacuation Responses Following Urban Nuclear Detonations, Report SAND20097507, November 2009. Sandia National Laboratories, Albuquerque, NM (For more information email lbrandt@sandia.gov.)

[24] Planning Guidance for Response to a Nuclear Detonation, $2^{\text {nd }}$ Edition, produced by Federal interagency committee led by the Executive Office of the President (National Security Staff and Office of Science and Technology Policy), June 2010.

[25] B. R. Buddemeier and M. B. Dillon, Key Response Planning Factors for Response to the Aftermath of Nuclear Terrorism, LLNL-TR410067.

[26] National Council on Radiation Protection and Measurements, Responding to a Radiological or Nuclear Terrorism Incident: A Guide for Decision Makers," Jan 2010. 